\title{
The Modification and Perfection of Advertisement Law under the Background of Network Implicit Advertisement Regulation
}

\author{
Huang Wei ${ }^{1, a}$ \\ ${ }^{1}$ Polytechnic institute of Jiangxi Science and Technology Normal University, Nanchang, Jiangxi, \\ 330100
}

Keywords: Advertising; Advertising Law; Advertising Law; Modification and Improvement

\begin{abstract}
With the development of economic globalization and the continuous progress of science and technology, the Internet has become an indispensable and important element in people's lives. Because more and more Internet users, many businesses found one of the opportunities, the implantation of advertising in the Internet is the era of information technology ad implantation of new forms. Although the "Advertising Law" in the legal provisions of the legal status of online advertising, but the release of online advertising in various forms, content is uncertain, very easy to drill "advertising law" loopholes. This paper mainly studies the hidden advertisements in online advertisements. Firstly, it explains the concept of network implicit advertisements. Secondly, according to the present situation of network hidden advertisements, it points out that the lack of advertising law under the regulation of network implicit advertisement, Reflections on Perfecting "Advertising Law".
\end{abstract}

\section{Introduction}

With the advent of the Internet information age, people can get more convenience through the network, while the use of the network to obtain a variety of information. According to statistics, online advertising in the advertising market share in the proportion of getting higher and higher, after 10 years of development, online advertising market share has been as high as $23.6 \%$. At the same time, with reference to turnover data, online advertising turnover grew at a high percentage. Comparing the turnover of online advertising with the turnover of magazine newspapers, it can be found that online advertising has become a tendency to become the largest advertising media. In 2015, Chinese new "Advertising Law" introduced, although this law has the terms of online advertising, but the actual implementation of the terms of the Internet can not solve the problems arising from, especially in the network of hidden advertising problem is extremely sharp The

\section{Network Implicit Advertising}

Internet advertising and traditional forms of advertising are different, the main carrier is the network. Network implicit advertising is the network as the main carrier advertising ads for covert publicity, network users can click on the information to see the specific content of advertising, network implicit advertising is the main purpose of advertising, so that their products get more attention. At present, the network implicit advertising manifestations are the following: in the form of news advertising, forum advertising, celebrity microblogging advertising, network soft paper advertising and keyword advertising. Contrast can be found, the network hidden ads than traditional advertising and even ordinary online advertising more hidden, can cause greater impact. First, the network hidden advertising takes through various forms to stimulate the consumer's subconscious, so that consumers of advertising and products to form a deep impression. Second, the network information age, network user platform replacement soon, but the network hidden ads can be well integrated into the various platforms. Third, the network hidden advertising has been able to get a lot of attention, or even get the trust of consumers and the key is the form of innovation. 


\section{Network Hidden Advertising Release Status Quo}

While online advertising is a change and innovation in which advertising follows the times, cyberspace advertising can lead to problems. Network implicit advertising due to the lack of clear legal supervision, the same appeared a lot of problems.

False advertising is very common in life, but people can learn through social experience and product inspection can identify the true and false advertising, so people read the traditional false advertising when deceived less. But the emergence of false network implicit advertising led to a large number of deceived consumers. Due to the virtual network, consumers can not see the product in kind, but can not make accurate judgments on product quality. Moreover, the false network of hidden advertising through various forms of innovation to stimulate consumer interest in shopping, reducing consumer psychology for online shopping.

Illegal advertising exists in real life, in the poles, platforms and other places posted a large number of illegal advertising, such as false advertising and other illegal advertising. Because the traditional advertising regulatory system is more comprehensive, illegal advertising can not be published in the traditional media. But with the rise of online media, the traditional view of advertising regulatory system can not be effective supervision of online advertising, resulting in a large number of online media appeared on the network hidden advertising. Because the lack of appropriate laws to review the online advertising, network operators are driven by the interests of a large number of illegal network hidden ads published to the network media, affecting the network environment.

Traditional advertising harassment generally in the form of telephone-based, low frequency of harassment, consumer psychology is also strong. In the online media, advertising harassment is particularly serious. Consumers almost every day to browse different sites, browse different online media, in the process, there have been a lot of web advertising. Web ads generally affect the reader's reading, and if the consumer tries to close it, it will open the ad link page. In addition to web advertising, e-mail advertising harassment is also more common, consumers to clear the mailbox in the online advertising, may cause the loss of useful information.

\section{Network Hidden Advertising Regulation under the "Advertising Law" Missing}

Chinese "advertising law" most of the content is basically set for the traditional advertising. But with the changes in the times, the advertising market content diversification, the form of advertising, advertisers, advertising operators and advertising publishers compared to the traditional advertising industry has changed. On the main issue of online advertising market, the current "Advertising Law" does not make clear on the main advertising market boundaries. Owners have the ability to create and publish ads, you can advertisers, advertising operators and the role of advertisers into one. This ambiguous advertising market positioning is not conducive to the online advertising market order maintenance.

Traditional advertising market has a strict market access assessment, the enterprise only through the certification to obtain a business license to enter the advertising market. But with the development of the Internet platform, the number of online advertising surge. In the "advertising law" legal system, the online advertising market access system is seriously missing, resulting in a variety of network users through a variety of network platform advertising, the community caused a bad impact.

The online advertising supervision system involves two aspects: advertising supervision and Internet supervision. But for now, Chinese "advertising law" under the legal system under the network regulatory system has not yet formed. From the number of online advertising point of view, only the unilateral power of the government can not build a network advertising regulatory system. 


\section{Revise and Improve the "Advertising Law" Thinking}

Modify and improve the "Advertising Law" need to do a lot of investigation of the actual situation, the current problems of online advertising on the fundamental nature of the analysis, and to improve the legal level. China is currently in the field of advertising only a "advertising law", in order to fundamentally solve the problem of network hidden advertising, China must strengthen the "advertising law" construction efforts. First of all, the legislature should conduct an in-depth investigation of the operation of online advertising, the operation of the various subjects in the process of the definition, while clarifying its legal status and responsibility. Second, the legislature needs to re-construct the specific provisions of the legal system of advertising law, the terms of which are related to the field of online advertising, need to be added. Finally, the legislature needs to establish clear guidelines for the recognition of advertising liability.

Chinese "advertising law" and even local advertising laws are not on the online advertising market access system to do a clear provision, which is the direct cause of the proliferation of online advertising. In the establishment of a sound online advertising market access system, China can learn from the experience of Western countries. Through the legislative form to establish and improve the online advertising market access system, clearly requires online advertisers must participate in the audit license before access to the advertising market. "Advertising Law" needs to issue a business license to make clear the standard, and a reasonable set of operating permit validity.

Due to the virtual nature of the Internet, online advertising supervision is more difficult. The construction of online advertising supervision system can not be achieved by the power of the government. To ensure the effectiveness of online advertising supervision and the comprehensiveness of online advertising supervision, the construction of online advertising supervision system requires comprehensive government agencies, network advertising operations review departments and the masses. The online advertising operation review department is responsible for the daily online advertising supervision, the illegal online advertising and its network publisher information submitted to the government, the government according to the information provided by the actual investigation, if the situation is true, according to the "advertising law" to complete law enforcement.

\section{Conclusion}

With the advent of the information age, people rely more and more on the Internet. At present, the problem of online advertising on people's legitimate rights and interests of a threat is not conducive to building a safe and green network environment. China needs to accelerate the "advertising law" perfect pace, through the improvement of legal provisions, the establishment of online advertising market access system and the construction of online advertising regulatory system to achieve the "advertising law" to modify and perfect, and ultimately achieve the long-term development of online advertising market.

\section{References}

[1] Zhang Jianhua. Accurately grasp the three legal boundaries of advertising law to protect advertising activities in the track of the rule of law [J]. China Business Administration Research, 2015, (10): 8-11.

[2] Wang Xianmao. The practice of grass-roots law enforcement to see "advertising law" to improve and perfect [J]. China Business Administration Research, 2014, (07): 12-13 + 26

[3] Lin Chengduo, Yang Yuping. Study on legal issues of online advertising supervision [J]. Journal of North China Electric Power University, 2012, (05): 49-55 